\section{BADN celebrates 80 years with virtual afternom tea}

BADN, the UK's professional association for dental nurses, celebrates 80 years of supporting dental nurses in 2020 - but its planned celebrations had to be put on hold because of the COVID pandemic.

'We had several events planned' said BADN President Jacqui Elsden, 'but these have all - including the Anniversary Afternoon Tea at the NEC Hilton in May had to be postponed.

'However, dental nurses are resilient and resourceful - so we decided to hold a "virtual" afternoon tea via Zoom, where we could "present" our long service badges and also the 2020 BADN Outstanding Contribution to Dental Nursing

Professional Practice Award.'

Almost 100 dental nurses who signed up for the Tea were sent a box containing a commemorative booklet on afternoon tea, teabags and a chocolate brownie with the BADN logo from EatMyLogo.

Guests were able to participate in two competitions: an online Quiz, organised and hosted by BADN's Adam Skalski where guests were able to answer questions via a downloaded phone app, won by Rebecca Silver who received an $£ 80$ voucher for

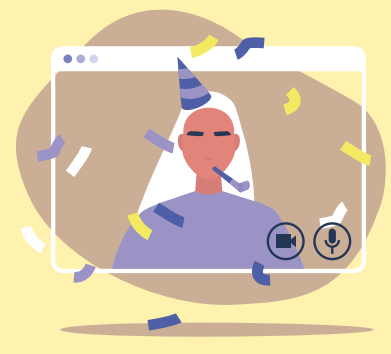

afternoontea.co.uk; and a baking competition won by Sasha Twyford with her Rugby Cake and Schnauzer cupcakes.

Long service membership badges were presented to Sherilee Bannerjee (25 years), Linda Day (20 years), Mandy Sheraton (15 years), Michelle Hesp (ten years), Katie Joyce and Sarah Sexton (five years). The 2020 BADN Outstanding Contribution to Dental Nursing Professional Practice Award was presented to Dr Debbie Reed, who had the previous day delivered the webinar hosted by CSM - organisers of The Dentistry Show - on the history of dental nursing.

England CDO Sara Hurley described the Tea as 'a thoroughly enjoyable afternoon, a celebration of talent and innovation in bringing together an awesome group of women from across the UK. It is an honour and a privilege to be involved with such a dynamic group of individuals.

BADN hopes to be able to hold its AGM and Drinks Reception in central London in early November 2020, depending on circumstances.
SBDN TO HONOUR LOCAL DENTAL NURSES IN THE COMMUNITY

In November 2020 the Society of British Dental Nurses (SBDN) will celebrate and honour the achievements of the remarkable dental nurses who helped, cared for and reached out to others in very challenging times during the COVID-19 pandemic.

SBDN Chair Emma Riley said: 'The helping and selflessness that has shone through as teams have had to adapt at pace, has been truly remarkable.

'Acts of determination, perseverance and resilience as part of the wider team, must be acknowledged. The recognition is not simply for clinical work, but for leading, planning and coordinating services, for time given to emergency work, for work in the local community and supporting the mental health and well-being of others looking out for colleagues.

Nominations can be made for dental nurse teams or individuals and the closing date is 2 October 2020.

The nominees will be shortlisted and winners announced live on National Dental Nurses Day, 22 November 2020.

All nominees will be recorded on the Society Local heroes list.

For further information email admin@ bdns.org.uk or call 07437481182 .

\title{
OUTSTANDING CONTRIBUTION TO DENTAL NURSING AWARD
}

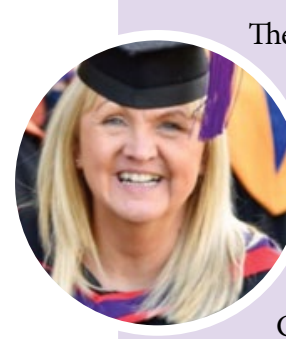

The BADN 2020 Outstanding Contribution to Dental Nursing Professional Practice Award was presented to Dr Debbie Reed at the BADN $80^{\text {th }}$ Anniversary Virtual Afternoon Tea.

Dr Reed, a former BADN

Chairman, trained as a dental nurse at the Royal Navy School of Dental Training in 1987. She went on to hold varying clinical and non-clinical posts over the next 20 years, in the UK and overseas, until she left the Royal Navy in 2007 and joined the staff at the University of Kent.

Dr Reed graduated from the University of Southampton with a BA (Hons) in Post Compulsory Education, gaining an MSc in Human Resource Development from the University of Portsmouth's Business School. Her teaching qualifications include a postgraduate teaching certificate in Higher Education from the University of Kent and a Certificate in Post Compulsory Education from the University of Southampton. In 2011 she was awarded Fellowship of the Higher Education Academy and in 2008 Chartered Member status with the Chartered Institute of Personal Development. She is registered with the General Dental Council (GDC) and holds a number of additional professional and vocational qualifications and awards in education, leadership and management.

In terms of publications and development work, Dr Reed authored the Teamwork and Leadership module for the joint NHS and the Faculty of General Dental Practice (UK) EDEN e-learning project in 2011 and in 2009 served as part of the GDC's Dental Nurse Project Feedback Group, developing new learning outcomes for dental nurse registration. Other contributions include the KSS Postgraduate Dental Deanery DNART project in 2009 and the Faculty of General Practice (UK) Teamwork 7 training package, published in 2007. She remains a member of the panel of examiners for the NEBDN since 1996, an affiliate member of the FGDP (UK) and Module Convenor Teamwork Module Faculty of General Dental Practice MSc in Primary Dental Care since 2008. She regularly publishes in dental journals; her articles are aimed at raising awareness of some of the broader professional characteristic and issues relevant to dental nursing and extending the professionalisation of dental nursing.

BADN President Jacqui Elsden said: 'It gives me great pleasure to present the 2020 BADN Outstanding Service to Dental Nursing Professional Practice Award to Dr Debbie Reed. Over the last 25 years or more, Debbie has contributed to the advancement of dental nurses across many areas of dentistry and has not only inspired me to achieve my potential but has inspired many others to do so and has recently acquired her doctorate in Education, one of only a handful of dental nurses to do so. 